\title{
PENERAPAN METODE PERSEDIAAN PROBABILISTIK UNTUK MENGHITUNG KEBUTUHAN BAHAN BAKU (STUDI KASUS DI PT. XZY)
}

\author{
Ade Suhara \\ Program Studi Teknik Industri, Universitas Buana Perjuangan Karawang \\ Jln.HS. Ronggowaluyo Telukjambe Timur, Karawang 41361 \\ Email : ade.suhara@ubpkarawang.ac.id
}

\begin{abstract}
Abstrak:
PT. XYZ merupakan perusahaan pembuatan kemasan jerigen plastik, bahan baku yang digunakan untuk memproduksi jerigen yaitu HDPE Titanvene, PP Cosmoplene, LDPE Cosmothene, dan Pewarna. Kebutuhan bahan baku pada PT. XYZ yang berfluktuatif dilihat dari keadaan pada waktu menjelang permintaan pemesanan jerigen banyak dari perusahaan lain. Sehingga berdampak terhadap stock bahan baku, yang dimana satu bulan cukup memenuhi kebutuhan produksi dan kadang bahan baku masih tersisa.

Tujuan dari penelitian ini adalah mengendalikan persediaan bahan baku yang optimal untuk mengefisienkan total biaya persediaan dengan menggunakan metode persediaan probabilistik model $Q$ dengan back order. Prosedur pengolahan data yang dilakukan dalam penelitian ini yaitu melakukan analisis klasifikasi ABC untuk menentukan jenis bahan baku yang termasuk kedalam kategori A. Lalu setelah itu dilakukan pengujian distribusi normal data kebutuhan bahan baku untuk mengetahui data tersebut normal atau tidak. Kemudian dilakukan pengolahan data menggunakan metode persediaan probabilistik model Qback order.

Kata Kunci: Pengendalian Persediaan, Metode $Q$ probabilistik, Safety Stock, Biaya Total.
\end{abstract}

\section{PENDAHULUAN}

Pengendalian persediaan merupakan aktivitas mempertahankan jumlah persediaan pada tingkat yang dikehendaki. Pada barang, pengendalian persediaan ditekankan pada pengendalian material. Persediaan berfungsi untuk mempermudah jalannya operasi perusahaan yang dilakukan secara berturut-turut untuk proses bisnis. Jika jumlah persediaan terlalu banyak maka akan menimbulkan dana menganggur yang besar, menambah biaya penyimpanan, dan resiko kerusakan bahan baku. Sedangkan, jika persediaan terlalu sedikit maka akan terjadinya kekurangan persediaan (Stock Out) dan 
sering terjadi pemesanan bahan baku tidak dapat didatangkan secara mendadak yang akan mengganggu proses produksi, dimana akan merugikan suatu perusahaan.

Dalam hal pengadaan bahan baku, pihak PT. XYZ yaitu masih menggunakan sistem pengendalian persediaan berdasarkan perkiraan, dilihat dari keadaan pada waktu menjelang permintaan pemesanan jerigen banyak dari perusahaan lain. Pada waktu adanya pemesanan perusahan menerima pesanan yang cukup banyak dan hal tersebut menyebabkan jumlah persediaan bahan baku menjadi cepat habis dan perlu adanya pesanan ulang atau (reorder point). Sehingga hal tersebut berdampak terhadap stock bahan baku, yang dimana satu bulan cukup memenuhi kebutuhan produksi dan kadang bahan baku masih tersisa. Maka dari itu dalam penelitian ini penulis mencoba untuk melakukan penelitian dalam optimalisasi perencanaan persediaan bahan baku pembuatan jerigen yang ada di PT. XYZ dengan pendekatan model Q Probabilistic.

\section{TINJAUAN PUSTAKA}

\subsection{PersediaanBahan Baku}

Menurut Bahagia (2006) persediaan di definisikan suatu sumber daya menganggur (idle resources) yang keberadaannya menunggu proses lebih lanjut. Yang dimaksud dengan proses lebih lanjut dapat berupa kegiatan produksi seperti dijumpai pada sistem manufaktur, kegiatan pemasaran seperti yang dijumpai pada sistem distribusi, ataupun kegiatan konsumsi seperti dijumpai pada sistem rumah tangga, perkantoran dan sebagainya.

\subsection{ManajemenPersediaan}

Sistem pengendalian persediaan barang dagang ataupun persediaan bahan baku harus dilaksanakan seefektif mungkin dalam suatu perusahaan untuk mencegah dan menghindari terjadinya kelebihan maupun kekurangan persediaan.

Menurut Harjanto (2008:237) dalam jurnal Siska (2013), Sistem pengendalian persediaan dapat didefinisikan sebagai serangkaian kebijakan pengendalian untuk menentukan tingkat persediaan yang harus dijaga, kapan pemesanan untuk menambah persediaan harus dilakukan dan berapa pesanan yang harus diadakan. 


\subsubsection{Jenis - JenisPersediaan}

Menurut Bahagia (2016) dalam suatu sistem manufaktur, inventori dapat ditemui sedikitnya dalam tiga bentuk sesuai keberadaannya, yaitu: Persediaanbahanbaku, Persediaanbarangsetengahjadi, danPersediaanbarangjadi.

\subsubsection{Biaya - BiayaPersediaan}

Menurut Nasution (2006) dalam jurnal Integra (2013) ongkos persediaan adalah semua pengeluaran dan kerugian yang ditimbulkan akibat persediaan. Ongkos tersebut adalah biaya pembelian, biaya pemesanan, biaya penyimpanan, dan biaya kekurangan persediaan.

Menurut Bahagia (2006) Biaya persediaan adalah semua pengeluaran atau kerugian yang timbul sebagai akibat adanya persediaan, baik yang berupa biaya yang berwujud atau biaya yang tidak berwujud. Adapun jenis-jenis biaya persediaan yang terdiri dari:Biaya pembeliaan, BiayaPengadaan, Biaya Simpan, dan Biaya Kekurangan.

\subsection{Model PersediaanProbabilistik}

Menurut Bahagia (2006) model persediaan probabilistik yaitu suatu keadaan persediaan yang mengandung ketidak pastian.

\subsubsection{Model $Q$ (Continuous Review Method)}

MenurutBahagia (2006) sistempersediaan model Q iniseringdisebutjugaFixed Order Size Inventory System and Countinous Review System.Model persediaan ini disarankan untu kmelakukan monitoring secara intensif atas status inventori untuk mengetahui kapan saat pemesanan dilakukan (r) dan ukuran lot pemesanan (q) selalu tetap untuk setiap kali pemesanan dilakukan.

\subsection{Analisis ABC}

Pada prinsipnya analisis $\mathrm{ABC}$ adalah mengklasifikasikan jenis barang yang didasarkan atas tingkat investasi tahunan yang terserap di dalam penyediaan persediaan untuk setiap jenis barang (Bahagia, 2006). Berdasarkan prinsip pareto, barang dapat diklasifikasikan menjadi tiga kategori, yaitu : Kategori A (80-20) : Menyerap dana sekitar $80 \%$ dan jumlah jenis barangnya sekitar $20 \%$ dari semua jenis barang yang dikelola, Kategori B (15-20) : Menyerap dana sekitar 15\% dan jumlah jenis barangnya sekitar 30\% 
dari semua jenis barang yang dikelola, Kategori C (5-50) : Menyerap dana hanya 5\% dan jumlah jenis barang sekitar 50\% dari semua jenis barang yang dikelola.

\subsection{Uji Normalitas dengan Kolmogorov Smirnov}

Menurut Rinto (2012) menyatakan dalam penelitian nya uji normalitas data dengan menggunakan metode Uji Kolmogorov-Smirnov yang merupakan suatu pengujian untuk membandingkan distribusi data (yang akan di uji normalitasnya) dengan distribusi normal baku. Distribusi normal baku adalah data yang telah ditransformasikan kedalam bentuk ZScore dan di asumiskan normal.

Pengujian hipotesis dilakukan dengan membandingkan nilai simpangan maksimum dan nilai kritis pada tabel Kolmogorov-Smirnov satu sampel atau melihat probabilitas yang ada. Dasar pengambilan keputusan adalah sebagai berikut :

1. Jika nilai $\mathrm{D}$ max hitung < $\mathrm{D}$ tabel maka $\mathrm{H}_{0}$ diterima, dan sebaliknya.

2. Jika probabilitas $>0,05$ maka $\mathrm{H}_{0}$ diterima, dan sebaliknya

\section{METODELOGI PENELITIAN}

\subsection{Langkah - Langkah Penelitian}

1. Identifikasi Masalah Masalah yang terjadi adalah perusahaan dalam mengendalikan persediaan masih berdasarkan perkiraan.

2. StudiLiteratur Studiliteratur berisi mengenai teori-teori yang dibutuhkan untuk penelitian.

3. StudiLapangan

Studi lapangan dilakukan untuk melihat kondisi actual dari perusahaan.

4. Pengumpulan Data

Data yang diperlukan untuk memecahkan masalah adalah jumlah kebutuhan bahan baku tahun 2016, jumlah pemesanan bahan baku tahun 2016, biaya pemesanan dan biaya penyimpanan, harga bahan baku, dan lead time.

5. Pengolahan Data

Pengolahan data untuk memecahkan masalah ini adalah pengelompokan jenis bahan baku dengan analisis $\mathrm{ABC}$, pengujian normalitas kebutuhan bahan baku, perhitungan $Q$ probabilistik, perhitungan safety stock, perhitungan reorder point, dan perhitungan total biaya prsediaan. 
6. AnalisadanPembahasan

Analisa dan pembahasan ini berdasarkan dari rumusan masalah yaitu mengendalikan persediaan bahan baku yang optimal di PT XYZ dan mengefesiensikan penggunaan biaya bahan baku jenis HDPE TITAN VENE.

7. Kesimpulandan Saran

Kesimpulan dan saran tersebut didapatkan dari hasil penelitan yang telah dilakukan. Setelah ditarik kesimpulan maka saran-saran dapat diajukan untuk perusahaan agar dapat dipergunakan ditahun-tahun yang akan datang.

3.2 Langkah-langkah dalam menentukan jumlah pemesanan dengan menggunakan model $Q$ probabilistik.

1. Hitung nilai $\mathrm{q}_{01}{ }^{*}$ awal dengan formula Wilson

$$
q_{01}^{*}=\sqrt{\frac{2 A D}{h}}
$$

2. Berdasarkan nilai $\mathrm{q}_{01}{ }^{*}$ akan diperoleh dapat dicari besarnya kemungkinan kekurangan persediaan.

$$
\begin{aligned}
& \alpha=\frac{h q_{01}^{*}}{c_{u} D}\left(z_{\alpha} \text { dapat dicari dari tabel A }\right) \\
& \alpha=\int_{r^{*}}^{\infty} f(x) d x \text { dimana, } r_{1}^{*}=D_{L}+z_{\alpha} S \sqrt{L}
\end{aligned}
$$

3. Dengan diketahui $\mathrm{r}_{1}{ }^{*}$ yang diperoleh akan dapat dihitung nilai $\mathrm{q}_{02}{ }^{*}$ dengan rumus sebagai berikut:

$$
q_{02}^{*}=\sqrt{\frac{2 D\left[A+c_{u} \int_{r_{1}^{*}}^{\infty}\left(x-r_{1}^{*}\right) f(x) d x\right]}{h}}
$$

Dimana : $\alpha=\frac{h q_{03}^{*}}{c_{u} D}$

$N=\int_{r_{1}^{*}}^{\infty}\left(x-r_{1}^{*}\right) f(x) d x=S_{L}\left[f_{(z \alpha)}-z_{\alpha} \Psi_{(\mathrm{z} \alpha)}\right]$

Nilai $f_{(Z \alpha)}$ dan $\Psi_{(z \alpha)}$ dapat dicari dari Tabel B.

4. Hitung kembali besarnya nilai $\alpha=\frac{h q_{03}^{*}}{c_{u} D}$ dan nilai $\mathrm{r}_{2}{ }^{*}$ dengan menggunakan :

$$
\alpha=\int_{r_{2}^{*}}^{\infty} f(x) d x \text { dimana, } r_{2}^{*}=D_{L}+Z_{\alpha} S \sqrt{L}
$$


5. Bandingkan nilai $r_{1}{ }^{*}$ dan $r_{2}{ }^{*}$, jika harga $r_{2}{ }^{*}$ relative sama dengan $r_{1}{ }^{*}$ iterasi selesai dan akan diperoleh $\mathrm{r}^{*}=\mathrm{r}_{2}{ }^{*}$ dan $\mathrm{q}_{0}{ }^{*}=\mathrm{q}_{02}{ }^{*}$. Jika tidak kembali kelangkah $\mathrm{c}$ dengan mengganti nilai $\mathrm{r}_{1}{ }^{*}=\mathrm{r}_{2}{ }^{*}$ dan $\mathrm{q}_{01}{ }^{*}=\mathrm{q}_{02}{ }^{*}$.

a. Persediaan Pengaman (Safety Stock)

$$
s S=z_{\alpha} S \sqrt{L}
$$

b. Ekspektasi ongkos total per tahun.

$$
O_{T}=D \rho+\frac{A D}{q_{0}}+h\left(\frac{1}{2} q_{0}+r-D_{L}\right)+C_{U} \frac{D}{q_{0}} \int_{r_{1}^{*}}^{\infty}(x-r) f(x) d x
$$

\section{Pengumpulan dan Pengolahan Data}

\subsection{Pengumpulan Data}

Data yang dibutuhkan dalam menentukan jumlah pemesanan yang optimal dengan model $Q$ probabilistic yaitu sebagai berikut :

1. Jumlah kebutuhan bahan baku tahun 2016

2. Jumlah pemesanan bahan baku tahun 2016

3. Biaya pemesanan, biaya penyimpanan, biaya kekurangan, harga bahan baku, dan lead time.

\subsection{Pengolahan Data}

Pengolahan data dalam penelitian ini yaitu sebagai berikut :

1. Pengelompokan jenis bahan baku dengan analisis $\mathrm{ABC}$

Sumber : Perhitungan Metode ABC

\begin{tabular}{|c|c|c|c|c|c|c|c|}
\hline $\mathrm{N}_{0}$ & Kode Barang & Nama Barang & $\begin{array}{c}\text { Presentase } \\
\text { Penyerapan } \\
\text { Dana }(\%)\end{array}$ & $\begin{array}{c}\text { Presentase } \\
\text { Kumulatif } \\
\text { Penyerapan } \\
\text { Dana }(\%)\end{array}$ & $\begin{array}{l}\text { Presentase Item } \\
\text { Jenis Barang }(\%)\end{array}$ & $\begin{array}{c}\text { Presentase } \\
\text { Kumulatifitem jenis } \\
\text { barang }(\%)\end{array}$ & Kategori \\
\hline 1 & HD $5401 \mathrm{GA}$ & HDPE TITANVENE & 86,25 & 86,25 & 10 & 10 & A \\
\hline 2 & JB $1544 \mathrm{M}$ & PE PEONY BLUE & 4,85 & 91,09 & 10 & 20 & B \\
\hline 3 & JB $3103 \mathrm{M}$ & PEPEONY BLUE & 3,97 & 95,06 & 10 & 30 & B \\
\hline 4 & AV 161 & PP COSMOPLENE & 2,01 & 97,06 & 10 & 40 & C \\
\hline 5 & MP 586 AZ & PEBLACK & 1,69 & 98,75 & 10 & 50 & $c$ \\
\hline 6 & F 410 & LDPECOSMOTHENE & 0,64 & 99,39 & 10 & 60 & c \\
\hline 7 & L 8160 & PE WHITE & 0,61 & 100,00 & 10 & 70 & C \\
\hline
\end{tabular}

Tabel 3 Presentase Kumulatif Penyerapan Dana

Sumber: Perhitungan Metode ABC

2. Uji Distribusi Normal

Untuk membuktikan data tersebut berdistribusi normal maka data kebutuhan bahan baku di uji ke normalan nya menggunakan program Statistical Program for 
Social Science (SPSS) versi 19 dan perhitungan manual menggunakan Microsoft

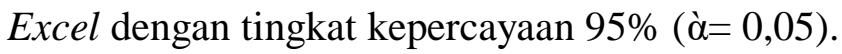

Tabel 4 Uji Normalitas Menggunakan SPSS Statistics19

One-Sample Kolmogorov-Smirnov Test

\begin{tabular}{|cc|r|}
\hline \multicolumn{2}{|c|}{ N } & \multicolumn{1}{c|}{ Demand } \\
\hline \multirow{2}{*}{ Normal Parameters ${ }^{\mathrm{a}, \mathrm{b}}$} & Mean & 12 \\
& Std. Deviation & 43768,5000 \\
Most Extreme & Absolute &, 206 \\
Differences & Positive &, 164 \\
& Negative &,- 206 \\
& Kolmogorov-Smirnov Z &, 714 \\
Asymp. Sig. (2-tailed) &, 688 \\
\hline
\end{tabular}

a. Test distribution is Normal.

b. Calculated from data.

Sumber: Pengolahan Uji Normalitas SPSS Statistics 19

Tabel 5 Uji Normalitas Menggunakan Microsotf Excel

\begin{tabular}{ccccccc}
\hline $\begin{array}{c}\text { Demand } \\
\text { (a) }\end{array}$ & $\begin{array}{c}\text { Frekuensi } \\
\text { (b) }\end{array}$ & $\begin{array}{c}\text { Kumulatif } \\
(\mathbf{c})\end{array}$ & $\mathbf{S}_{\mathbf{n}}(\mathbf{x})(\mathbf{d})$ & Z-Score $(\mathbf{e})$ & $\mathbf{F}(\mathbf{x})(\mathbf{f})$ & $\begin{array}{c}\text { Difference } \\
(\mathbf{g})\end{array}$ \\
\hline 24508 & 1 & 1 & 0,083333333 & $-1,877306273$ & 0,03023806 & 0,053095269 \\
26168 & 1 & 2 & 0,166666667 & $-1,540878966$ & 0,06167312 & 0,104993544 \\
28761 & 1 & 3 & 0,25 & $-1,015265781$ & 0,15498958 & 0,095010424 \\
31409 & 1 & 4 & 0,333333333 & $-0,478340367$ & 0,31620398 & 0,017129349 \\
33930 & 1 & 5 & 0,416666667 & 0,032818303 & 0,51309026 & 0,096423592 \\
35311 & 1 & 6 & 0,5 & 0,31278583 & 0,62277831 & 0,122778309 \\
36017 & 1 & 7 & 0,5833333333 & 0,45591188 & 0,67577333 & 0,092439994 \\
36176 & 1 & 8 & 0,666666667 & 0,488105105 & 0,6872623 & 0,020595636 \\
37838 & 1 & 9 & 0,75 & 0,824897323 & 0,79528506 & 0,045285057 \\
38008 & 1 & 10 & 0,8333333333 & 0,859421921 & 0,80494611 & 0,028387223 \\
38508 & 1 & 11 & 0,916666667 & 0,96086707 & 0,83169049 & 0,084976172 \\
38588 & 1 & 12 & 1 & 0,976983955 & 0,83571145 & 0,164288548 \\
\hline
\end{tabular}

\begin{tabular}{cc}
\hline Statis tik (i) & Varariabel 1 (j) \\
\hline N Sampel & 12 \\
Mean & 33768,517 \\
Simpangan Baku & 4932,715 \\
KS hitung $\left(D_{\mathrm{n}}=\right)$ & 0,164 \\
KS Tabel & 0,380 \\
\hline \multicolumn{2}{c}{ Normal } \\
\hline
\end{tabular}




\section{Sumber : Pengolahan Uji Normalitas Manual}

3. Pengolahan Data Probabilistik Model $Q$ dengan Back order

Perhitungan EOQ probabilistik untuk bahan baku HDPE TITAN VENE HD 5401 GA dengan back order yang bertujuan untuk mendapatkan hasil yang optimal diantara nya yaitu Safety Stock, Reorder Point, Quantity Order dan total inventory cost. Pengolahan data tersebut dapat dilihat padatabel 6.

Tabel 6 PerhitunganPengendalianPersediaanBahan Baku

\begin{tabular}{ccccc}
\hline \multirow{2}{*}{ Iterasi } & \multicolumn{4}{c}{ Jenis Bahan Baku HDPE TITANVENE } \\
& $\mathbf{q}^{*}=\mathbf{q} 02^{*}$ & $\mathbf{r 1}^{*}=\mathbf{r} \mathbf{2}^{*}$ & ss & Ot \\
\hline 1 & $20113 \mathrm{Kg}$ & $5335 \mathrm{Kg}$ & $1283 \mathrm{Kg}$ & $\mathrm{Rp} 7.165 .801 .746$ \\
\hline
\end{tabular}

Sumber : Pengolahan Data Model $Q$ probabilistik

Untuk menegaskan bahwa metode persediaan probabilistik model $Q$ back order merupakan metode yang cocok digunakan di PT. XYZ, maka dilakukan perbandingan dengan metode persediaan probabilistik model $P$ back order, hasil perbandingan model $Q$ dan model $P$ dapat dilihat pada tabel 7 .

Tabel 7. Hasil Perbandigan Model $Q$ dan Model $P$

\begin{tabular}{|c|c|c|c|}
\hline \multicolumn{2}{|c|}{ Model $Q$ back order } & \multicolumn{2}{|c|}{ Model $P$ Back order } \\
\hline $\begin{array}{l}\text { Jumlah Pemesanan Yang } \\
\text { Optimal (q0) (Kg) }\end{array}$ & 20113 & $\begin{array}{l}\text { Periode Waktu } \\
\text { Pemesanan (T) (Tahun) }\end{array}$ & 0,04 \\
\hline $\begin{array}{l}\text { Titik Pemesanan Kembali } \\
\text { ( R ) (Kg) }\end{array}$ & 5335 & $\begin{array}{l}\text { Inventori Maksimum } \\
\text { Yang Diharapkan ( R ) } \\
(\mathrm{Kg})\end{array}$ & 20262 \\
\hline $\begin{array}{l}\text { Persediaan Pengaman } \\
(\mathrm{ss})(\mathrm{Kg})\end{array}$ & 1283 & $\begin{array}{l}\text { Persediaan Pengaman } \\
(\mathrm{ss})(\mathrm{Kg})\end{array}$ & 1332 \\
\hline $\begin{array}{l}\text { Total Biaya Persedian } \\
\text { (OT) }(\mathrm{Rp})\end{array}$ & 7.165 .801 .746 & $\begin{array}{l}\text { Total Biaya Persediaan } \\
(\mathrm{OT})(\mathrm{Rp})\end{array}$ & 7.191 .819 .483 \\
\hline
\end{tabular}

Sumber : Rekapitulasi Hasil Pengolahan Data. 
Total biaya persediaan yang optimal dengan menggunakan pengolahan data model $Q$ back order menghasilkan total biaya persediaan sebesar Rp. 7.165.801.746,sedangkan menggunakan pengolahan data model $P$ back order menghasilkan total biaya persediaan sebesar Rp. 7.191.819.483,- Dengan demikian penerapan metode persediaan yang lebih optimal dan lebih efisien untuk PT. XYZ yaitu menggunakan Metode Persediaan Probabilistik Model Q back order.

\section{Analisa Dan Pembahasan}

\subsection{Analisa}

1. Analisa Pengelompokan Jenis Bahan Baku

Dari tujuh item jumlah bahan baku yang dipesan oleh PT. XYZ di klasifikasikan dengan analisis $\mathrm{ABC}$ dan diperoleh satu item bahan baku yang termasuk dalam kategori menyerap sumber dana yang paling besar dan jumlah kebutuhan paling banyak (kategori A) dengan jenis bahan baku yaitu HDPE TITAN VENE HD 5401 GA.

2. Analisa Pengendalian Persediaan Bahan Baku

Sistem Pengendalian Persediaan PT. XYZ yaitu masih menggunakan system pengendalian persediaan berdasarkan perkiraan. Adapun penggunaan system pengendalian persediaan dengan metode probabilistik model $Q$ yaitu bertujuan untuk mengetahui kapan saat pemesanan dilakukan (r) dan ukuran lot pemesanan ( $\left.q_{0}\right)$ selalu tetap untuk setiap kali pemesanan dilakukan.

3. Analisa Efesiensi Biaya Bahan Baku

Dalam mengefesiensikan biaya penggunaan bahan baku HDPE TITAN VENE, perusahaan memiliki perhitungan total biaya persediaan selama satu tahun yaitu sebesar Rp. 7.779.594.907,-. Sedangkan jika menggunakan metode persediaan probabilistik model $Q$ total biaya persediaan yang diperoleh menjadi sebesar Rp. 7.165.801.746,- .

Tabel 8 Perbandingan Biaya Total Persediaan 


\begin{tabular}{|c|c|c|c|c|}
\hline Nama Bahan Baku & & & \multicolumn{2}{|c|}{ HDPE TITANVENE } \\
\hline Kode Bahan Baku & & & \multicolumn{2}{|c|}{ HD $5401 \mathrm{GA}$} \\
\hline Jumlah Pemesanan per Tahun & & & \multicolumn{2}{|c|}{8 kali pemesanan } \\
\hline Harga per $\mathrm{Kg}$ & & & $\mathrm{Rp}$ & 17.600 \\
\hline Quantity (Kg) & & & & 405222,2 \\
\hline Total Harga & & & $\mathrm{Rp}$ & 7.131 .910 .720 \\
\hline Biaya Telpon (dikali jumlah pemesanan/tahun) & $\mathrm{Rp}$ & 110.000 & $\mathrm{Rp}$ & 880.000 \\
\hline Biaya Fax (dikali jumlah pemesanan/tahun) & $\mathrm{Rp}$ & 20.000 & $\mathrm{Rp}$ & 160.000 \\
\hline Biaya Internet per tahun & \multicolumn{2}{|c|}{12 bulan x 60.000} & $\mathrm{Rp}$ & 720.000 \\
\hline Biaya Bongkar /Kg (dikali Quantity) & $\mathrm{Rp}$ & 10 & $\mathrm{Rp}$ & 4.052 .222 \\
\hline Biaya Kerusakan dan Resiko Lain & & & $\mathrm{Rp}$ & 35.659 .554 \\
\hline Biaya Asuransi & & & $\mathrm{Rp}$ & 71.319 .107 \\
\hline Suku Bunga Bank & & & $\mathrm{Rp}$ & 534.893 .304 \\
\hline \multicolumn{3}{|c|}{ Total Biaya Persediaan Perusahaan } & $\mathrm{Rp}$ & 7.779.594.907 \\
\hline \multicolumn{3}{|c|}{ Total Biaya Persediaan dengan Metode Persediaan Probabilistik Model $Q$} & $\mathrm{Rp}$ & 7.165.801.746 \\
\hline \multicolumn{3}{|c|}{ Total Penghematan Biaya } & $\mathrm{Rp}$ & 613.793 .161 \\
\hline
\end{tabular}

Sumber: PT. XYZ

\subsection{Pembahasan}

1. Pengelompokan Jenis Bahan Baku

Hasil pengolahan data dalam pengelompokan jenis bahan baku dengan menggunakan analisa sistem $\mathrm{ABC}$, dari tujuh jenis bahan baku terdapat satu jenis bahan baku yang masuk kategori A yaitu HDPE Titan vene (HD 5401 GA) dengan menyerap dana perusahaan sebesar Rp.7.131.907.200,--

2. PengendalianPersediaan Bahan Baku

Dari hasil pengolahan data metode probabilistik model $Q$ diperoleh jumlah pemesanan yang optimal ( $\mathrm{q}_{0}$ ) yaitu sebesar 20113 Kg, Hasil pengolahan titik pemesanan kembali (reorder point) yaitu sebesar 5335 , Persediaan pengaman (safety stock) diperoleh sebesar $1283 \mathrm{Kg}$ dimana persediaan pengaman tersebut bertujuan untuk mengatasi stock out terhadap bahan baku HDPE TITAN VENE.

\section{EfesiensiBiayaBahan Baku}

Dengan perbandingan total biaya persediaan aktual dari perusahaan dengan total biaya persediaan yang telah dihitung menggunakan metode persediaan probabilistik model $Q$ dengan Back Order, maka dalam analisis ini perusahaan 
memiliki penghematan biaya yang cukup besar dari perhitungan menggunakan metode persediaan probabilistik model $Q$ dengan back order yaitu sebesar Rp. 613.793.161,--

\section{Kesimpulan Dan Saran}

\subsection{Kesimpulan}

Berdasarkan perumusan masalah yang telah diuraikan dari pengolahan data menggunakan klasifikasi $\mathrm{ABC}$ dan perhitungan metode persediaan probabilistik model $Q$ untuk mengendalikan persediaan bahan baku yang optimal dan mengefisienkan penggunaan biaya bahan baku, adalah sebagai berikut:

1. Berdasarkan analisis klasifikasi ABC dari tujuh item jenis bahan baku yang dipesan terpilih bahan baku HDPE TITAN VENE HD 5401 GA yang termasuk dalam kategori A.

2. Berdasarkan analisis klasifikasi ABC, terpilih bahan baku HDPE TITAN VENE HD 5401 GA. Dan dalam pengolahan data metode persediaan probabilistik model $Q$ back order diperoleh jumlah pemesanan yang optimal (quantity order) yaitu sebesar 20113 $\mathrm{Kg}$, titik pemesanan kembali (reorder point) sebesar $5335 \mathrm{Kg}$, dan persediaan pengaman (safety stock) sebesar $1283 \mathrm{Kg}$.

3. Total biaya persediaan bahan baku HDPE TITAN VENE tahun 2016 yang dihitung menggunakan metode persediaan probabilistik model $Q$ back order yaitu sebesar Rp.7.165.801.746,-. Dalam hal ini total biaya persediaan yang dihitung menggunakan model $Q$ back order dapat mengefesiensikan penggunaan biaya persediaan bahan baku HDPE TITAN VENE sebesar Rp. 613.793.161,-.

\subsection{Saran}

Sebagai tindak lanjut dari penelitian ini, ada beberapa saran yang dapat disampaikan kepada PT. XYZ mengenai pengendalian persediaan bahan baku yang lebih efektif dan efisien pada masa yang akan datang, yaitu anatara lain: 
1. Berdasarkan analisa sistem $\mathrm{ABC}$ untuk pengelompokan jenis bahan baku, terdapat satu jenis bahan baku yang masuk dalam kategori A yaitu HDPE Titan vene, sehingga perusahaan harus memperhatikan jenis bahan baku yang di prioritaskan.

2. Berdasarkan analisa data probabilistik model $Q$ back order, perusahaan dapat menetapkan nilai jumlah pemesanan yang optimal, titik pemesanan kembali dan persediaan pengaman, agar dapat meredam fluktuasi demand atau jumlah kebutuhan bahan baku HDPE TITAN VENE.

3. Dari hasil pengolahan data persediaan probabilistik model Q back order, perusahaan dapat menghemat biaya persediaan sebesar Rp.613.793.161,-. Sehingga perusahaan dapat mengestimasikan total biaya persediaan bahan baku HDPE TITAN VENE yang akan dibeli, agar dapat mengefesiensikan biaya persediaan.

\section{DAFTAR PUSTAKA}

Nur Bahagia, Senator., 2006. Sistem Inventori. Departemen Teknik Industri ITB, Bandung.

Tersine, R.J., 1988. Principles Of Inventory And Materials Management. Elsevier Science Publishing., Inc. New York.

Surianto, Agus., 2013. Penerapan Metode Material Requirement Planning di PT. Bokormas Mojokerto. Jurnal Ilmiah Mahasiswa, FEB UB. Juli 2013. Halaman 6.

Siska,. 2013. Analisis Sistem Pengendalian Persediaan Barang Dagang Pada PT. Sungai Budi di Palembang. Jurnal Ilmiah Mahasiswa. 2013. Halaman 2.

Integra, Reka., 2013. Rancangan Sistem Persediaan Bahan Baku Kain Pada Kondisi Demand Probabilistik Dengan Kendala Luas Gudang* (Studi Kasus CV. Visa Insan Mandini). Jurnal Online Institut Teknologi Nasional. Vol-1 No-1, Juli 2013, Halaman $78-91$.

Integra, Reka., 2015. Ukuran Jumlah Pemesanan Optimal Komponen Wedge dan Taper Pada Mesin Bubut Dengan Mengguakan Model Q (Continuous Review Method). Jurnal Online Institut Teknologi Nasional, Vol-3 No-3, Juli 2013, Halaman 78-91.

Sihotang, Rinto., 2012. Pengendalian Persediaan Bahan Baku Model Persediaan Probabilistik Dengan Sistem Kuantitas Pemesanan Tetap Pada PT. Central Proteina Prima, Tbk Medan. Fakultas Teknik Universitas Sumatra Utara, Medan. 